\section{Treating astrology's claims with all due gravity}

SIR - Isaac Newton postulated that there is a force of attraction between any two bodies in the Universe. Your News story 'Gravity passes a little test' (Nature 446, 31-32; 2007) points out that "Isaac Newton's inverse-square law of gravity has given faultless service ever since". I have found a curious way to use Newton's law to draw attention to the difference between science and anti-science for a general audience.

I teach an introductory science class at my university, which typically enrols many non-science majors. During a lecture on the gravitational force, I imply that if planets such as Mars exert a force on any object, including humans, then perhaps there is something to astrology's idea that celestial bodies exert a force of influence on our lives. I encourage my students to undertake a test I have designed for this notion.

I present the students with 12 randomly numbered horoscopes from the previous day, with the corresponding signs of the zodiac removed. I ask each student to record the horoscope that best describes the day she or he had, and the astrological sign (for example, Aries) corresponding to her/his birthday. My scientific hypothesis is that planets may exert a force on our bodies, but it is purely random -1 out of $12(8.3 \%)$ - whether a horoscope foretells the events of one's life.

I am pleased to report that, as Shawn Carlson has noted, "astrology failed to perform at a level better than chance" (Nature 318, 419-425; 1985). The results from my classes are: $8.0 \%$ ( $n=163$ students), $8.4 \%$ $(n=155), 7.0 \%(n=143), 8.0 \%(n=138)$ and $8.0 \%(n=100)$. In other words, as John Maddox has commented "astrology is a pack of lies ... There is no evidence that the positions of the planets can affect human behaviour" (Nature 368, 185; 1994).

I encourage science teachers to try this approach when they are presented with an opportunity, as this exercise inspires genuine scientific inquiry. For example, students have countered that a certain astrologer may not be qualified to read the stars. I have addressed this question by using horoscopes from different newspapers (Chicago Tribune, Columbus Dispatch, Los Angeles Times and Washington Post) and online sources (Astrology.com, DailyHoroscopes.com). Other students have noted that small groups, with only two students of a particular sign, may obtain a result that is significantly greater than $8.3 \%$. This presents an opportunity to discuss the value of an adequate sample size.

Finally, it is worth reporting that my students are so engaged by this exercise that they actually want to use Newton's law of universal gravitation to calculate force values.
In case you are curious, Mars, at its present distance of 264 million kilometres from Earth, is exerting a force of approximately 50 nanonewtons on your being.

Steven K. Lower

The Ohio State University, 275 Mendenhall Laboratory, Columbus, Ohio 43210, USA

\section{Conflict and cancer research in Arizona}

SIR - Your News Feature 'The Arizona experiment' (Nature 446, 968-970; 2007) mentions that Robert Pettit "lost" directorship of the Cancer Research Institute at Arizona State University, as though he were an absent-minded professor who had just misplaced it. In fact, after disagreements with the university's president Michael Crow, Pettit was removed from the position and the institute was effectively closed down. All the personnel were transferred to the university's Biodesign Institute. After a year of problems and disputes, which included measures taken to stop them obtaining any new funding, the group was terminated. The reasons given by Crow and the Biodesign Institute's head George Poste, according to articles that appeared in local newspapers, were that the research was out of date and that the group had not kept up with recent advances.

A less euphoric assessment of Crow's administration and its effect on morale can be found in an article by Megan Irwin in the Phoenix New Times (www.phoenixnewtimes. com/2007-04-26/news/asu-inc).

John C. Knight

13646 East Westland Road, Scottsdale, Arizona 85262-5850, USA

\section{Pathologists needed to cope with mutant mice}

SIR - The number of genetically engineered mouse mutants is rising substantially, as highlighted in your Editorial 'Mutant mice galore' (Nature 446, 469-470; 2007). However, there is insufficient manpower and expertise in comparative pathology to characterize and validate these model animals effectively. We ask the scientific community to recognize this crisis and help address the issue before it becomes catastrophic.

The International Mouse Knockout Consortium is creating a critical, but unmet, need for expert comparative pathologists knowledgeable in mouse biology and human disease. Effective mouse pathology requires an understanding of mouse biology and a knowledge base that is not possessed by most investigators or pathologists. Funding agencies recognize the problem, but are not sufficiently addressing it, and the funding mechanisms of the US National Institutes of Health do not allow for training in pathology. Where are the mouse pathologists of the future, and who is going to train them?

Scientists involved in creating the huge mutant-mouse population need to recognize this need and help find a solution. The governments funding the mice and their databases are failing to create the necessary human resources. One potential solution could be a partnership among academic institutions, industry and government to develop and support an 'electronic consortium' of existing mouse pathology specialists. Their collective wisdom could be shared with interested young pathologists, using distance-learning tools.

Robert D. Cardiff

Center for Comparative Medicine, University of California at Davis, Davis, California 95616, USA

\section{Open journals' records to give reviewers their due}

SIR - Sydney Brenner and Richard Robert's request in Correspondence (Nature 446, 725; 2007) for authors to conserve records of their work and make them freely accessible is of great importance to historians of science.

However, unlike an artist's preparatory sketches or a novelist's drafts, scientific papers describing major discoveries have gone through the process of peer review. Reviewers often make significant contributions in shaping discoveries. They suggest new experiments, propose novel interpretations and reject some papers outright. Clearly, this is also important 'behind the scenes' work by scientists usually at the forefront of their discipline, and is an intrinsic part of the scientific process. It is well worth keeping a record of such work, for no history of science will be complete and accurate without it.

I therefore propose that journals' records should be made publicly available after an adequate lapse of time, including the names of reviewers and the confidential comments exchanged between editors and reviewers. The Nobel Foundation makes all its records available after 50 years, as do many governmental and other institutions. This delay may be reduced for scientific journals to, perhaps, 15 or 20 years. This is also likely to have a positive impact on the peer-review process itself.

The scientific community and future historians will gain from this transparency and from full knowledge of all the events that have contributed to a great discovery.

\section{Ariberto Fassati}

Wohl Virion Centre and MRC-UCL Centre for Medical Molecular Virology, Division of Infection and Immunity, University College London Medical School, 46 Cleveland Street, London W1T 4JF, UK 